\title{
Cluster Analysis of Regional Competitiveness in the European Union and the Role of ICT
}

\author{
Marta-Christina Suciu \\ Adrian Petre ${ }^{2}$
}

\begin{abstract}
This article represents an empirical research on the competitiveness of the European Union Member Countries. The main objective is to analyze the level of competitiveness of these countries, focusing on the situation of the new non-Eurozone member countries. At the same time, we want to identify the main measures to stimulate competitiveness. The research methodology we applied is based on critical comparative analysis, statistical data and econometric analysis. The results showed that there are large gaps in competitiveness between the new EU Member Countries that are not part of the Eurozone and the EU-28 average, and even larger compared to the performers Netherlands and Germany, gaps that in the current conditions will be very difficult to be reduced. Research has also shown that ICT adoption do not have a significant impact on the competitiveness indicator, and the main factors influencing this indicator are innovation capability, financial system, institutions, business dynamism, product market and skills. Thus, we believe that for a sustainable growth of competitiveness and for meeting the economic objectives, developing countries must adopt concrete measures to develop these fundamental pillars of competitiveness.
\end{abstract}

Keywords: competitiveness, innovation, smart development, cluster, European Union

JEL Classification: 011, O30

DOI: $10.24818 / \mathrm{REJ} / 2021 / 82 / 01$

\section{Introduction}

Increasing the degree of competitiveness is one of the main objectives of all developed or developing countries, as a high degree of competitiveness of the national economy produces positive effects in the medium and long term at the microeconomic, mezzoeconomic and macroeconomic level. Even though a number of policies and measures for economic growth and competitiveness have

\footnotetext{
${ }^{1}$ University professor, PhD., Department of Economics and Economic Policies, The Bucharest University of Economic Studies, Romania, e-mail: christina.suciu@economie.ase.ro

${ }^{2}$ Independent researcher, PhD., Romania, e-mail: adrian.petre21@gmail.com

Year XXIV no. 82

December 2021
} 
been adopted so far, both at European and national level, there are still many challenges that need troubleshooting, based on sustainable and inclusive measures.

Territorial competitiveness is an important element for boosting sustainable economic development and for reducing productivity gaps between developed and developing countries, which makes this topic of high interest in economic research.

Given the importance of competitiveness on economic development, the main objective we have set for this scientific article is to analyze the level of competitiveness of the European Union (EU) Member Countries, focusing on the situation of the newest acceding countries that are not part of the Eurozone and have this desideratum (Romania, Bulgaria, Poland, Hungary, Czech Republic and Croatia), and also to identify the most appropriate measures to improve the level of competitiveness of these states in the shortest possible time.

Depending on the results obtained, we will be able to establish the extent to which the stimulation of a country's competitiveness can be correlated with the level of development and integration of information and communication technologies (ICTs).

\section{Literature review}

The international literature that addresses the issue of global and regional competitiveness is very extensive. According to Barro (1991), competitiveness is seen and debated in different ways and by reference to different dimensions: globally, nationally, regionally or at the business level.

Many scientific studies in this field analyze competitiveness in relation to drivers of smart development (smart capital, information and communication technologies, research and development, innovative entrepreneurship, and so on.), because the classical model of economics is increasingly becoming a model of the knowledge-based economy. For example, Gjelsvik (2018) considers that an effective measure for increasing competitiveness is the development of crosscutting innovation platforms, which creates a link between academia, the economy and local communities. On the other hand, Bojnec \& Fertő (2018) highlights the importance of removing barriers to business development, efficient mobility of inputs, attracting foreign direct investment and increasing the percentage of the population with tertiary education, as factors that stimulate global competitiveness.

The idea of stimulating the development of intellectual capital is also supported by other authors as the optimal measure for increasing competitiveness. Parausic et 
al. (2014) states that many European countries, such as Germany, Finland or the Netherlands, have increased their level of national competitiveness through investments in education and skilled labor, which have contributed to a high level of productivity. The same idea is supported by Čepar \& Bojnec (2010), who demonstrated that the extension of tertiary education has positive effects on the living standards of individuals and stimulates the growth of economies.

Further, in order to reach the stated goal we will analyze, based on econometric methods, the time evolution of the competitiveness of EU countries by forming clusters.

\section{Competitiveness clusters in the European Union}

In this section we will try to identify the way in which the European Union Member Countries are grouped in competitiveness clusters, as well as their intercluster movement during the period 2005-2017. The organization of these states in groups with similar characteristics will allow us to make a comparative analysis and to draw certain conclusions regarding their evolution over time and the trend of the competitiveness convergence.

Fischer and Stirböck (2004) define convergence clusters as the process by which each region belonging to a particular cluster moves from an unbalanced position to its equilibrium position within the cluster.

Cluster analysis uses grouping algorithms through which certain elements are classified into homogeneous groups. The grouping of elements is done in such a way as to maximize the variation between groups and to minimize the variation within a group.

Cluster analysis involves the following steps:

- Identifying and recording the important variables in grouping the factors;

- Calculating the distance between factors;

- Creating the proximity matrix;

- Choosing the cluster algorithm needed to generate groups.

The first stage consists in organizing the statistical data in a matrix in which the variables are on columns and the cases are on the line. The object of classification is represented by cases.

The second stage involves measuring the distance between the elements. In this sense we will use the Euclidean distance method, which represents the length of the line segment that joins two points $\mathrm{p}_{1}$ and $\mathrm{p}_{2}$ : 


$$
d(x, y)=\sqrt{\sum_{i}\left(x_{i}-y_{i}\right)^{2}}
$$

To determine the Euclidean distance between the EU-28 average and the states included in the analysis, we will use the Global Competitiveness Index (GCI), which is annually determined by the World Economic Forum (WEF).

Variables will be rescaled with values between 0 and 1, using the following formula:

$$
z_{i}\left(y_{i}\right)=\frac{y_{i}-\text { the lower limit of } y}{\text { the upper limit of } y \text {-the lower limit of } y}
$$

The third stage consists in determining the proximity matrix based on the calculated Euclidean distances.

In the fourth stage are identified rules for assessing the distances between the clusters obtained. The method used in this case is K-means.

The operation of the K-means method is as follows:

- Step 1: randomize the initial $k$ centers;

- Step 2: Each center is assigned the courts closest to it;

$$
C_{(i)}=\arg \min \left\|X_{1}-m_{k}\right\|^{2}, i=1, \ldots, N
$$

- The center of gravity (arithmetic mean) of all the courts assigned to a center is calculated and the center position of the respective group is updated:

- Repeat the two steps until the position of any center does not change.

The cluster analysis is applied at the level of the European Union Member Countries, and the focus is on the situation of the new countries that are not yet part of the Eurozone.

The reference period is 2005-2017 in order to capture both the pre-accession and post-accession period to the European Union of the states included in the analysis.

Following the methodology described above, we obtained six competitiveness clusters at the level of the European Union, according to Table 1. Cluster 1 includes the most performing countries and Cluster 6 the least performing. 
Table 1. Competitiveness clusters in the European Union

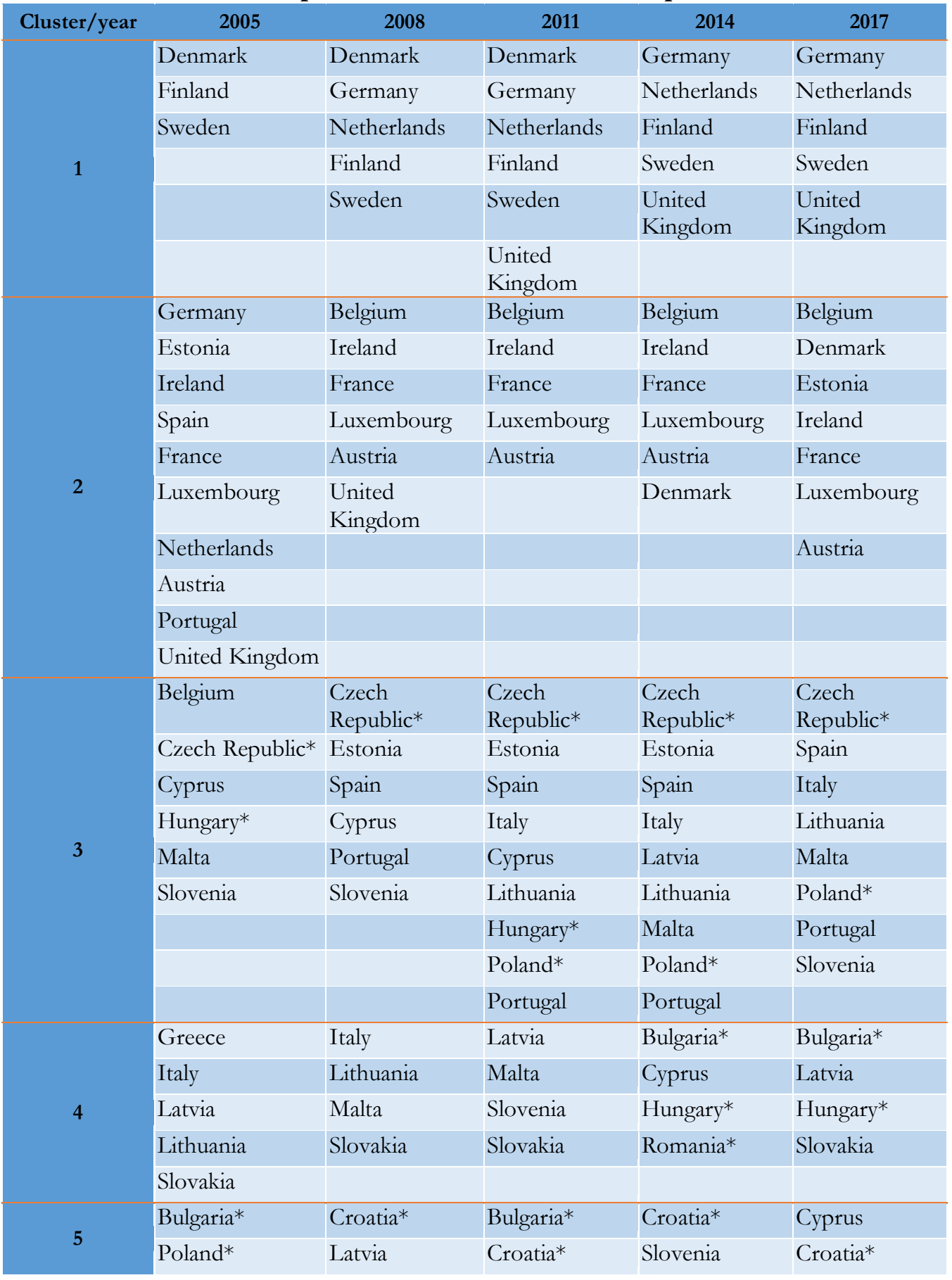




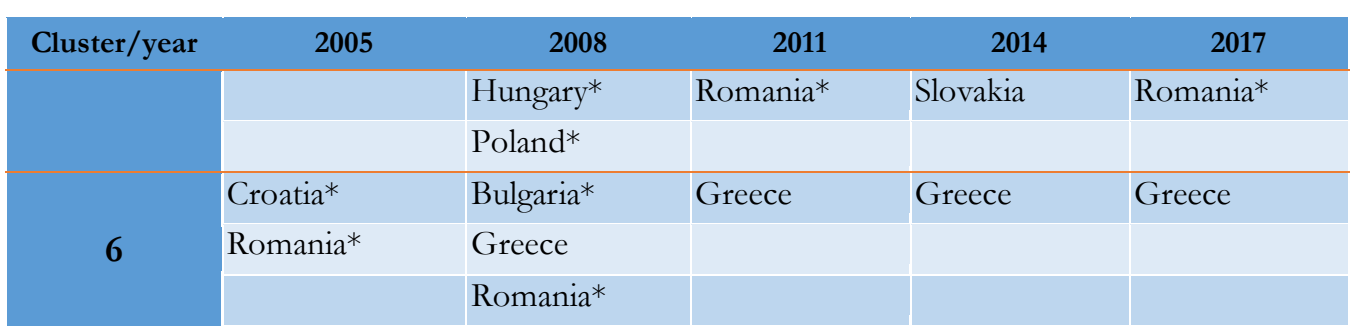

*the new Member Countries of the EU that are not part of the Eurozone (states that joined EU after 2000) Source: made by the authors

The data in Table 1 show that during the analyzed period the countries that are classified exclusively in Cluster 1 are Finland and Sweden. Starting with 2008, this cluster is completed with Germany and the Netherlands, and from 2011 the United Kingdom is part of it also.

Denmark, which in the period 2005 - 2011 was located in Cluster 1, registered a decline in the following period, ranking in Cluster 2. All countries in Cluster 1 are practically the best performing countries in the European Union in terms of competitiveness, being at the longest distance from the EU-28 average.

The other countries that are above the EU-28 average are those in Cluster 2, and as we can see a constant presence in this cluster is that of Austria, Ireland, France and Luxembourg.

On the other hand, the countries that are located in Clusters 3, 4, 5 and 6 register a level of competitiveness below the EU-28 average, with Cluster 6 having the lowest performances. An almost constant presence in this cluster is that of Greece, which managed a better ranking only in 2005 (Cluster 4).

Of the new non-Eurozone EU Member Countries, the best performance is recorded by the Czech Republic, which is located throughout the period in Cluster 3 , which is made up of the countries closest to the EU-28 average. Similar performances are in the case of Poland, this country having an important progress starting with 2011 when it managed to advance from Cluster 5 to Cluster 3 and to maintain this position. The third most competitive country in this category is Hungary, which was located in Cluster 3 in 2005 and 2011, and since 2014 is part of Cluster 4.

The less developed countries in terms of competitiveness, both at the aggregate level within the European Union, as well as the category the new Member Countries outside the Eurozone are Bulgaria and Romania. Of these countries, Bulgaria was placed on a better position in the last two analyzed periods, namely Cluster 4, while in the case of Romania the best ranking was in 2014 (Cluster 4), 
otherwise this country stood only in the weakest performance clusters, and in 2017 was the second lowest after Greece in terms of distance from the EU-28 average.

Another important aspect to note is that, in the case of four of the new nonEurozone EU Member Countries (Poland, Hungary, Bulgaria and Romania), there has been an increase in the convergence of competitiveness with the EU-28 average after accession.

All these results show that it is imperative for these countries to adopt sustainable measures in order to significantly increase their competitiveness, so as to benefit from positive long-term economic effects and to fulfill the assumed integration objectives.

\section{Measures to increase the degree of competitiveness}

Kelley et al. (2016) conducted a study in which they showed that the main gaps related to innovative performances are one of the important causes of differences between levels of economic development. Similar to this empirical study, Dima et al. (2018) conducted an research through which they demonstrated that there is a strong correlation between competitiveness and innovation.

Consistent with the results of these studies, we can assume that one of the main measures to be implemented at the level of the new non-Eurozone EU Member Countries in order to stimulate the level of competitiveness is to invest heavily in innovation capacities (for example: the development of human capital and permanent integration of information and communication technologies in economic and social activities).

To test our hypothesis, that the position of countries in the competitiveness ranking depends on their ability to innovate, and also to confirm or refute the results of the studies conducted by Kelley et al. (2016) and Dima et al. (2018), we will test the connection between each of the pillars of the Global Competitiveness Index 4.0 calculated by the World Economic Forum and the aggregate value of the WEF GCI for the European Union Member Countries. The data refer to 2019.

This link will be tested using the correlation coefficient. The results of the correlations between the stated indicators are presented in Table 2 . 
Table 2. The correlations between WEF GCI pillars and WEF GCI, 2019

\begin{tabular}{|l|c|}
\hline \multicolumn{1}{|c|}{ WEF GCI pillars } & WEF GCI overall \\
\hline Institutions & 0.92 \\
\hline Infrastructure & 0.80 \\
\hline ICT adoption & 0.48 \\
\hline Macroeconomic stability & 0.56 \\
\hline Health & 0.50 \\
\hline Skills & 0.85 \\
\hline Product market & 0.90 \\
\hline Labor market & 0.72 \\
\hline Financial system & 0.93 \\
\hline Market size & 0.53 \\
\hline Business dynamism & 0.91 \\
\hline Innovation capability & 0.97 \\
\hline Saure: & \\
\hline
\end{tabular}

Source: made by the authors based on the Global Competitiveness Report 2019

The data in Table 2 show that the dominant pillar of GCI is Innovation capability, which has the strongest correlation with aggregate WEF GCI. This confirms our hypothesis and the results of the studies conducted by Kelley et al. (2016) and Dima et al. (2018) that the degree of innovation has a significant influence on the level of competitiveness and economic development of countries.

Other pillars with a significant impact on the competitiveness of states are: the financial system, institutions, business dynamism, product market and skills.

It should be noted that ICT adoption plays a less important role in supporting the countries competitiveness, the correlation coefficient between this indicator and WEF GCI being the lowest (0.48).

Based on the results obtained in this section, we can say that in order to increase the level of competitiveness, the new EU Member Countries that are not part of the Eurozone must invest heavily in innovation capacities. At the same time, as we have shown, it is imperative to give special importance to the financial system and state institutions.

Even if there is a low direct correlation between ICT adoption and WEF GCI, ICT solutions should not be ignored, as they can make an important contribution to innovation strategies.

All these cumulative measures can produce important benefits for the countries that implement them, leading to increased competitiveness, which supports 
sustainable economic growth and ultimately, achieving the goal of adopting the euro.

\section{Conclusions}

National and regional competitiveness are extremely important and intensely debated topics in the scientific literature, as it has a special importance in the context of globalization.

Our work is a contribution to the research carried out so far in terms of global competitiveness within the European Union and different drivers that can explain its evolution. Our analysis regarding the situation of the European Union Member Countries shows that there is a group of countries that almost constantly maintain their position in the cluster of the best performing European countries in terms of competitiveness, and these are: Germany, the Netherlands, Finland, Sweden and UK. On the other hand, the weakest countries are Greece, Romania, Bulgaria and Croatia, which are permanently in the last competitiveness clusters.

It should be noted that all EU countries that are not part of the Eurozone have a level of competitiveness below the EU-28 average throughout the analyzed period, but the trends are slightly positive in the case of four of them (Poland, Hungary, Bulgaria and Romania), which recorded an increase in the degree of competitiveness convergence with the EU-28 average after accession.

These results demonstrate the imperative of adopting complex and sustainable measures, and our study showed that stimulating innovation capacity is the main tool for increasing the level of competitiveness. At the same time, the measures adopted by these countries must focus on the development of the following pillars: the financial system, institutions, business dynamism, product market and skills.

Another very important conclusion is that ICT adoption does not have a great influence on the competitiveness indicator of countries, but we consider that the measures to increase the competitiveness mentioned above must take into account and integrate ICT solutions.

Finally, we propose that, in order to increase the level of competitiveness and achieve the desideratum of adopting the euro, the acceding countries must develop masterplans focused mainly on large investments in research and development, highly qualified human capital, ensuring the stability and development of the governmental framework and permanent support for innovative entrepreneurship. 


\section{References}

Barro, R. J. 1991, "Economic Growth in a Cross Section of Countries", Quarterly Journal of Economics, 106(2), pp. 407-443. https://doi.org/10.2307/2937943

Bojnec, Š. \& Fertô, I. 2018, "Globalization and outward foreign direct investment", Emerging Markets Finance \& Trade, 54 (1), pp. 88-99. https://doi.org/ 10.1080/1540496X.2016.1234372

Čepar, Ž. \& Bojnec, Š. 2010, "Higher education demand factors and the demand for tourism education in Slovenia", Organizacija, 43(6), pp. 257-266. https://doi.org/10.2478/v10051-010-0026-x

Dima, M. A., Begu, L., Vasilescu, D. M., \& Maassen, A. M. 2018, "The relationship between the knowledge economy and global competitiveness in the European Union", Sustainability, 10(6), 1706. https://doi.org/10.3390/su10061706

Fischer, M. M. \& Stirböck, C. 2004, Regional Income Convergence in the Enlarged Europe 1995-2000: A Spatial Econometric Perspective, ZEW Discussion Paper, No. 04-42.

Gjelsvik, M. 2018, "Universities, innovation and competitiveness in regional economies", International Journal of Technology Management, 76(1/2), pp. 1031. https://doi.org/10.1504/ijtm.2018.088704

Kelley, D. J., Singer, S., \& Herrington, M. 2016, The global entrepreneurship monitor, 20152016 Global Report. Retrieved from http://www.gemconsortium. org/report.

Paraušić, V., Cvijanović, D., Mihailović, B., \& Veljković, K. 2014, “Correlation between the state of cluster development and national competitiveness in the Global Competitiveness Report of the World Economic Forum 20122013”, Economic Research - Ekonomska Istrą̌ivanja, 27(1), pp. 662-672. https://doi.org/10.1080/1331677X.2014.974917

World Economic Forum, The Global Competitiveness Reports 2005 - 2019, Geneva, Switzerland. 